\title{
An improved algorithm in unipolar weather radar calibration for rainfall estimation
}

\author{
A. Nikahd ${ }^{1}$ M. Hashim ${ }^{1} \cdot$ M. J. Nazemosadat ${ }^{2}$
}

Received: 31 July 2015/Accepted: 15 February 2016/Published online: 10 May 2016

(C) Springer International Publishing Switzerland 2016. This article is published with open access at Springerlink.com

\begin{abstract}
Weather unipolar ground-based radar estimation can experience momentous changes by using other effective parameters such as distance from radar, altitudes and rainfall time duration that directly compromise the accuracy of the hydrometeorology applications. These radar measurements however, need to be calibrated for more accurate rainfall estimation. In addition to the radar-rainfall $(\mathrm{Z}-\mathrm{R})$ relationship, this is a pragmatic approach based on careful analyses of other parameters. This article introduces a new calibration approach using altitude parameters and time-stepwise processing of reflectivityrainfall $(\mathrm{Z}-\mathrm{R})$ rate relationship. This research leads to introduce a new effective parameter and generate two new empirical coefficients in radar-rainfall relationship. Two consecutive years unipolar ground-based radar data sets with 190 occurrences of rainfall from 43 stations in calibration window of $3 \mathrm{~h}$; and the corresponding rainfall measured from registered rain gauges were used in this study. The results indicated that radar-rainfall relationship $Z=A R^{b}$ is better improvised with altitudes effect $(\mathrm{H})$ and empirical coefficient (c), such that $Z=A R^{b} H^{c}$. It therefore is concluded that the use of other effective parameters (distance from radar, altitudes and rainfall time duration) leads to optimum accuracy of Z-R relationship.
\end{abstract}

A. Nikahd

Ali.nikahd@yahoo.com

1 Institute of Geospatial Science and Technology (INSTeG), Universiti Teknologi Malaysia (UTM), 81310 Johor Bauru, Malaysia

2 Department of Water Engineering, Institute of Atmosphere, Ocean Research Centre, Shiraz University, Shiraz, Fars Province, Iran
Keywords Radar-rainfall relationship · Altitudes · Calibration

$\begin{array}{ll}\text { Abbreviation } \\ \text { GBR } & \text { Ground based radar } \\ \text { db } & \text { Decibel } \\ \text { PPI } & \text { Plan position indicator } \\ \text { CAPPI } & \text { Constant altitude plan position indicator } \\ \text { SRI } & \text { Surface rain intensity } \\ \text { IMO } & \text { Iran meteorological organisation } \\ \text { RHI } & \text { Range height indication } \\ \text { GHZ } & \text { Gigahertz } \\ \text { ANN } & \text { Artificial neural network } \\ \text { AI } & \text { Artificial inteligent } \\ \text { FL } & \text { Fuzzy logic } \\ \text { SVM } & \text { Support vector mashin } \\ \text { TRMM } & \text { Tropical rainfall measurement mission } \\ \text { WSR } & \text { World surveillance radar } \\ \text { Zh } & \text { Horizontal reflectivity } \\ \text { Zv } & \text { Vertical reflectivity } \\ \text { DSD } & \text { Drop size distribution }\end{array}$

\section{Introduction}

Rainfall forecasting and flood prediction involve using ground-based radar and are dealt as most important topics in hydrometeorology, civil engineering and natural resources management. Reflectivity data from groundbased radar provides high spatial and sequential information on the characteristics of volume and amount of rainfall. Radars cannot accurately estimate the amount of rainfall before being calibrated due to many sources of error announced by the ground topography and atmosphere. Many studies have been done about the radar- 
rainfall estimation but, there is less attention to the accuracy of the output in different altitudes [1], distance from radar [2, 3] and rainfall duration times $[4,5]$. There are large differences between the amount of real rainfall and predicted amount. The fluctuations in the rainfall prediction amount may be not too important in light rainfall mode, but in the heavy precipitation is irreparable damage, especially in mid-latitude regions. The main factor in forecasting errors is the multiplicity of uncertainty sources in the atmosphere. The greatest way to achieve an ideal radar prediction is calibration and adjustment radars by effective parameters such as; altitudes, distance from radar, rainfall types and etc.

In this paper, we investigate the effects and properties of the altitude and rainfall time duration in radar-rain gauges relationship for ground-based radar calibration. Since 1948, weather ground-based radars were used in predicting rainfalls based on Marshal-Palmer proposed relationship [6]. According to this universal relationship, there is a strong correlation between the rate of the radar reflectivity $(\mathrm{Z})(\mathrm{dB})$ and the rainfall amount $(\mathrm{R})(\mathrm{mm} / \mathrm{h})$ that is known the $\mathrm{Z}-\mathrm{R}$ relationship.

Return signal from atmospheric targets are dimensionless information and called dimensionless radar output (DRO). The DRO value is the 8 bit alteration of audio-visual motion that ranges between 0 and 255 dimension integer [7, 8]. Although, there are a strong relationship between $\mathrm{Z}$ and $\mathrm{R}$ in $Z=A R^{b}$ equation, this does not mean that reflectivity from radar is exactly equal to the amount of rainfall $[9,10]$. The $\mathrm{A}$ and $b$ are empirical coefficients which refer to climatological characters, location of rainfall, rainfall seasons, geographic latitudes [11, 12] and rainfall time duration [13, 14]. The empirical coefficients depend on climate characteristic in each area exclusively [15], and were used to determine Z-R relationships and relevant regional coefficient [16]. More than 100 relationships are available for different rainfall forms such as strait form, tropical, convective, thunderstorm, shower, monsoon and hurricanes [9]. The sensitivity variation of $Z-R$ relationships are the main uncertainty sources [17], especially in rainfall calculation based on drop size distribution (DSD). Because of radar measurements carry many uncertainty sources depending on dissimilarities of radar reflectivity in the atmosphere; radar calibration is unavoidable, in order to estimate the amount of rainfall precisely [18, 19]. Consequently the values of $A$ and $b$ coefficients varies from place-toplace, season-to-season, and time-to-time.

As most of the improbability occurs more far from the radar, the distance from the radar is a main factor in all of uncertainty sources [20]. Most errors are found away from the radar [21]. This means that majority of the uncertainty is related to dimension from the radar [22]. The distance (d) between overshooting reflectivity (radar station) and the location of drop raining is very important parameters to ground-based radar calibration. Previous studies have shown that this calibration can further improved radarrainfall estimation by use of multiple Z-R relationship [2325] rainfall types [26], distance from the radar [27, 28] and other parameters [29]. These parameters vary with different weather situations such as rain types, rain duration and seasons which rain occurs.

In addition to the above calibration, this study also hypothesizes a new improvement of the universal Z-R relationship, taking into account the effects of altitude $(\mathrm{H})$ and distance from radar (D) and other new coefficient $\mathrm{c}$. Thus producing new improved algorithm for the relationship is such that $Z=A R^{b} H^{c}$. The radar zones are defined in circular shape from the center of radar station. The effects of distance in rainfall estimation are investigated in 0-50 km (zone 1), 50-100 km (zone 2), 100-150 km (zone 3) and $150-200 \mathrm{~km}$ (zone 4) from the radar. The hourly rainfall products from the registered rain gauges were used in this study.

\section{Radar-rainfall relationship}

It is assumed that raindrop shapes are spherical and sizes are smaller than the radar wavelength. There are special equations between reflectivity and the characteristics of rain drops. It is important to qualify radar reflectivity $(\mathrm{Z})$ because the reflectivity depends on the number and diameter of raindrops on the radar sample volume [30]. The reflectivity $(\mathrm{Z})$ is dependent of number, diameter and velocity of raindrops;

$Z=\sum_{i} N_{i} D_{i}^{6}=\int_{0}^{\infty} N(D) D^{6} d D$

and

$R=\frac{\pi}{6} \int_{0}^{\infty} N(D) D^{3} V_{t}(D) d D$

where $\mathrm{Z}\left(\mathrm{mm}^{6} / \mathrm{m}^{3}\right)$ is reflectivity, $\mathrm{R}(\mathrm{mm} / \mathrm{h})$ is the rainfall rate, $\mathrm{N}(\mathrm{D}) \mathrm{dD}$ is the mean sum of raindrops, $\mathrm{D}(\mathrm{dD})(\mathrm{mm}) /$ $\mathrm{m}^{3}$ of air $\left(N_{i}\right.$ is the number of drops with $D_{i}$ the diameter of the $i$ th element), and $V_{t}(\mathrm{~cm} / \mathrm{s})$ is the droplet terminal velocity. If the above Eqs. $(1,2)$ with respect to the similarity parameters equivalent to each other, then Eq. (3) will be;

$Z \propto R$

This means there are strong relationships between reflectivity and the amount of rainfall. According to this 
strong relationship, the $\mathrm{A}$ and $\mathrm{b}$ coefficient has been found consequence of improve the Eq. (3);

$Z=A R^{b}$

It is assumed that heights (altitudes) are more effective parameter in radar-rainfall estimation.

$Z=A R^{b} H^{c}$

Here we try to improve Eq. (4) and corroborate Eq. (5).

\section{Materials and methods}

\section{Unipolar ground-based radar}

Unipolar ground based radar in Tabriz, Iran (latitude: $37^{\circ} 55 \mathrm{~N}$, longitude: $46^{\circ} 10^{\prime}$ and $1700 \mathrm{~m}$ height) is used in this study. Figure 1 shows the location and configuration of Tabriz's radar station with the zones of data acquisition. The area of coverage by this radar footprint is between $36^{\circ} 01^{\prime}$ until $39^{\circ} 20^{\prime}$ in semi-arid zone at northern hemisphere.

Tabriz radar is C-band radar that is located close the Tabriz city in $37^{\circ} 50^{\prime} \mathrm{N}$ with $3.75 \mathrm{~cm}$ wavelength and 5.6 GHZ that is serviced by $250 \mathrm{kw}$ transmitter power. The antenna diameter is $6.7 \mathrm{~m}$. The Doppler range is $200 \mathrm{~km}$ and non-Doppler range is $400 \mathrm{~km}$; spatial resolution is $1 \times 1 \mathrm{~km}$. Details are shown in Table 1 . This station has the capability of producing; RHI, PPI, CAPPI and SRI. This study, however, only used plan position indicator (PPI). The entire Tabriz radar station is managed by Iran Meteorological Organization (IMO) and is under the national weather radar network. The main radar data acquire reflectivity numerical amount per decibel $(\mathrm{dB})$ unit. These data processed by using the RAINBOW software

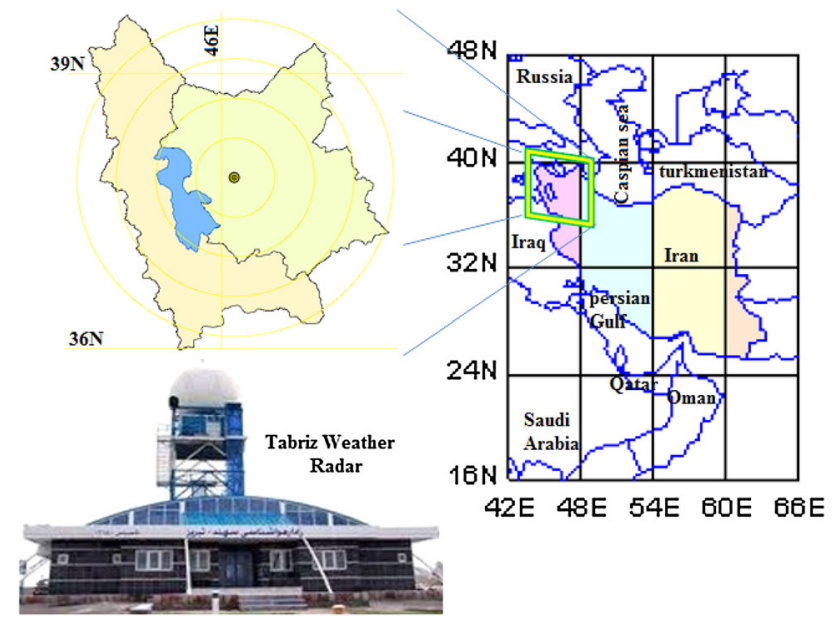

Fig. 1 Location of Tabriz radar and Azarbayjan province in the world
Table 1 Characteristic of Tabriz radar

\begin{tabular}{ll}
\hline The characteristic of radars & TABRIZ radar \\
\hline Peak power & $250 \mathrm{kw}$ \\
Wave length & $3.75 \mathrm{~cm}$ \\
Type of band & $\mathrm{C}$ \\
Antenna diameter & $6.7 \mathrm{~m}$ \\
Receiver & Logarithmic \\
Elevation angle & $0.5^{\circ}$ \\
Samples pr. rotation (vertical) & $0-360$ \\
Samples pr. rotation (horizontal) & $(2)-(182)$ \\
Spatial resolution & $1 \times 1 \mathrm{KM}$ \\
Data output frequency & $5-15 \mathrm{~min}$ \\
Antenna rotation speed( round per second) & 6 \\
Polarization (vertical/horizontal) & $\mathrm{V}$ or H \\
Oscillation frequency transmitter & $5.62 \mathrm{GHZ}$ \\
Scanning strategy single layer and continuous & \\
\hline
\end{tabular}

that converting radar reflectivity data into decibel unit. The rainfalls are typically in reflectivity range between 5 and $75 \mathrm{~dB}$; light rain begins at $5 \mathrm{~dB}$ and hails at $80 \mathrm{~dB}$, respectively. Four zones surrounding the radar station are introduced, as this radar zonation can show distance changes between reflectivity and rainfall location.

\section{Rain gauges network}

More than 190 rainfalls occurred in East Azerbaijan and West Azerbaijan providence during the period of study from 1st January 2011 to 30th December 2012. The rainfall is regulated based on hourly basis. We investigated $3 \mathrm{~h}$ of rainfall from the moment the rain starts. Two types of rain gauges station were employed, namely: synoptic and climatological station. There are 43 stations (12 climatology stations and 31 synoptic stations) under Tabriz radar. These stations are equipped with registered rain gauges, scattered in the radar-introduced zones. Figure 2 shows rain gauges locations surrounding Tabriz radar. These rain gauges are pluviometer with registered pen that is extracted from special graph based on 1-h observation. Minimum and maximum hourly registered rainfall is $0.1-2.2 \mathrm{~mm}$ in this weather period.

\section{Calibration process}

The basic background of this theory for this study is that, for each altitude one can estimate the Z-R relationship. Also, the $\mathrm{Z}-\mathrm{R}$ relationship changes are considerable in each step time of rainfall duration. Accordingly, the two relationship were investigated based on multiple regression 


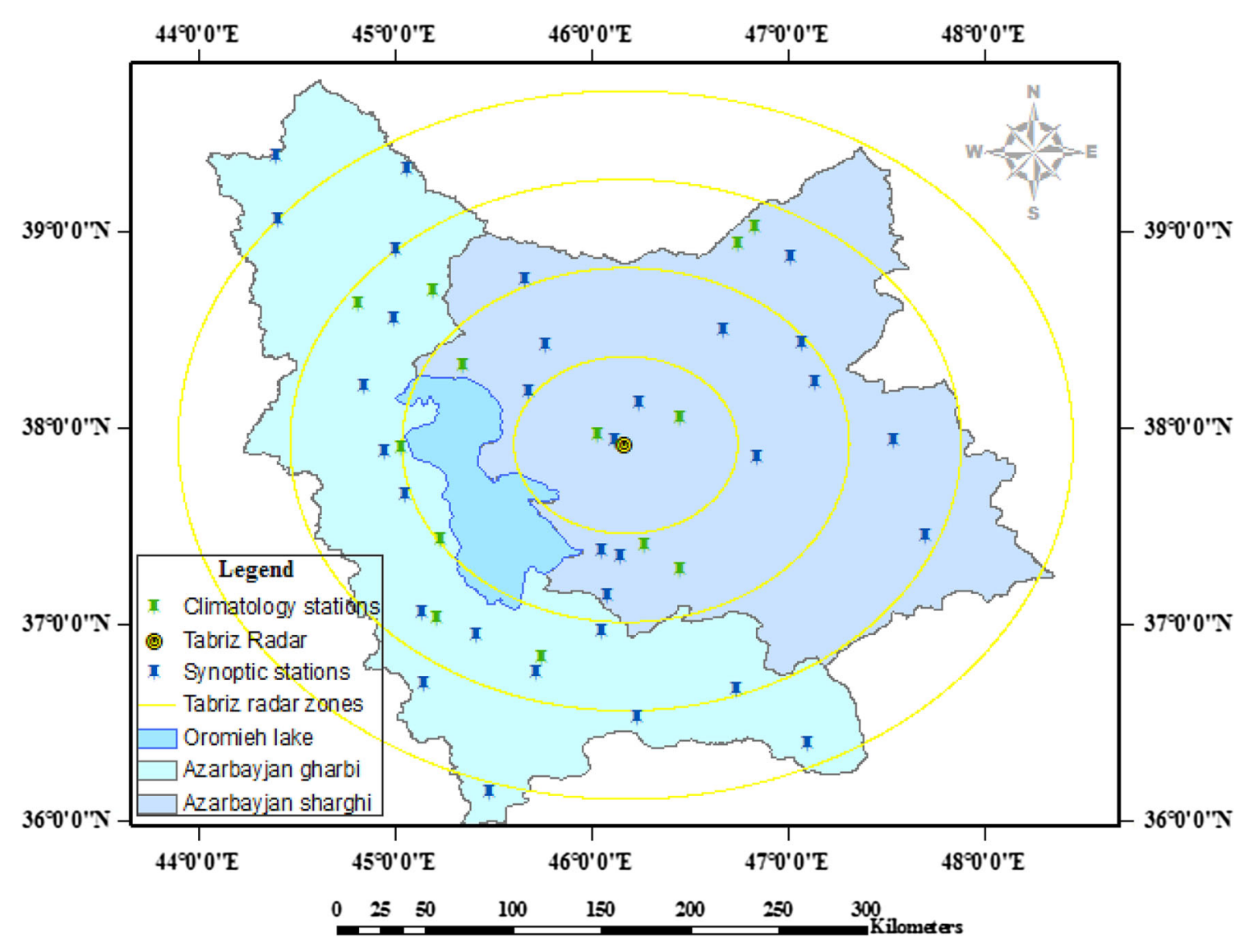

Fig. 2 Location of rain gauges network in Tabriz radar zonation

analyses. At first, the relationship started with simple mode; relationship between one independent variable and one dependent variable. Rainfall $(\mathrm{mm} / \mathrm{h})$ in all equations is independent variable and radar reflectivity $(\mathrm{dB})$ is dependent variable. Variable is arranged based time hourly. According to the general relationship (Marshal-Palmer), the equation is:

$Z=a R^{b}+e$

This relationship is extended for all stations that is collection in 3 hours of rainfall in all the four zones surrounding the radar.

$Z_{t_{i} z_{i}}=a_{i} R_{t_{i} z_{i}}^{b \mathrm{i}}+e_{t_{i} z_{i}}$

where $\mathrm{Z}$ is radar reflectivity, $\mathrm{R}$ is rainfall amount, $t_{i}$ is rainfall time duration, 1 th-2th-3th $\mathrm{h}$ of rainfall; here were investigated 3 time of rainfall from rainfall start until 3th time of rainfall based hourly. The $z_{j}$ introduces four zones: zone1 $\quad(0-50 \mathrm{~km}), \quad$ zone2 $\quad(50-100 \mathrm{~km}), \quad$ zone3 (100-150 km), zone4 (150-200 km). The coefficient $a_{i}$ and $b_{i}$ are the empirical coefficients and $e_{t_{i} z_{j}}$ are partial errors in each zone and time, respectively. Taking into account all of the data in a coordinate system, we can to reach Eq. (8);
$Z_{t}=a R_{t}^{b}+e$

The $(\mathrm{t})$ is mean; using all data in the entire region of rainfall in one coordinates.

The second relationship investigated is to find new matrix mode of data with effects of altitude differences. This parameter was first introduced in this paper. When the factor $\mathrm{H}$ is considered in the second relationship, the coefficient $\mathrm{c}$ is generated; created as a novel empirical coefficient that is dependent on the geomorphology of rainfall locations. Here after, c coefficient is called "altitude coefficient". The new relationship is then introduced in Eq. (9); such that;

$Z=a R^{b} H^{c}+e$

This relationship is experimented in $3 \mathrm{~h}$ of rainfall occurrences in 4 defined zones center about Tabriz radar station.

$Z_{t_{i} z_{j}}=a_{i} R_{t_{i j} j}^{b \mathrm{i}} H_{n}+e_{t_{i} z_{j}}$

Equation (10) parameters are exactly the same as in Eq. (7), the only difference is $H_{n}$. The $H_{n}$ shows altitude changes at each point where the rainfall is measured. 
Taking into account all of the data in a coordinate system, and $t$ is the total of data, then equation can be expressed as:

$Z_{t}=a R_{t}^{b} H_{n}^{c}+e_{t}$

As a result, Eq. [11] presents the relationship between reflectivity and all parameters and coefficients in all data in all places and all times of precipitation, respectively. However, previous studies have determined the relationship between reflectivity and rainfall amount based on power regression [3, 4, 14, 17, 24, 25, 27, 31-34]. But, it is possible that the relationship could be manifested in other matrix form such as; logarithmic or exponential regression. All earlier works based on Marshall-Palmer relationships, have however, used only the power-based function in the regression analysis for all the parameters involved. In this paper, ArcGIS v9.3 is used for locating rain gauges and related distances for formation of the radar zones, whilst the MATLAB was used in all the numerical data analysis in this study.

\section{Results}

The radar-rainfall relationship improvement is to find the other effective parameters which are defined as the determining factor between real rainfall and the corresponding radar rainfall estimates. In this study, radar-rainfall relationship has been developed for processing and analyzing 2 years consecutive rainfall data from unipolar groundbased radar in middle latitudes. The results indicated that the altitude effects can be added as a new parameter in radar-rainfall equation. The $\mathrm{Z}-\mathrm{R}$ relationship was investigated with the introduction of new additional effective parameters. In the following stages of the study, we achieved two main results include: (1) demonstrating the strength Z-R relationship and, (2) detection of the effects of altitude in radar-rainfall relationship and to introduce new equation $\mathrm{Z}-\mathrm{R}-\mathrm{H}$ in radar-rainfall relationship.

1. Determination of relationship between $(R)$ and $(Z)$; there are strong relationship between radar reflectivity and rainfall amount in cold semi-arid zone in the middle latitudes and relevant coefficient. Z-R relationship is investigated in all zones and 3 time of rainfall time duration. Table 2 shows the amount of empirical coefficient (a,b) and relationship between variables in 4 zones and 3 times of rainfall. There are no significant differences between value obtained and other research in middle geographic latitudes. We found the range of coefficients of variation; $(68<\mathrm{a}<104)$ and $(0.81<\mathrm{b}<1.85)$. Table 2 tabulates the detailed results, where a new coefficient $\mathrm{a} / \mathrm{b}$ is introduced to enable changes in coefficient a with
Table 2 Summary of coefficient $(a, b, a / b), R$-square and RMSE from $\mathrm{Z}-\mathrm{R}$ fitting

\begin{tabular}{lrllll}
\hline Time/Coe & \multicolumn{1}{l}{$\mathrm{a}$} & $\mathrm{b}$ & $\mathrm{a} / \mathrm{b}^{*}$ & $\mathrm{R} 2(\mathrm{p}<0.05)$ & $\mathrm{RMSE}(\mathrm{mm} / \mathrm{h})$ \\
\hline Zone 1 & & & & & \\
1th & 104 & 0.95 & 109.5 & 0.77 & 0.14 \\
2th & 96 & 0.81 & 118.5 & 0.70 & 0.22 \\
3th & 99 & 0.88 & 112.5 & 0.81 & 0.23 \\
Zone 2 & & & & & \\
1th & 75 & 1.59 & 47.2 & 0.95 & 0.05 \\
2th & 74 & 1.57 & 47.1 & 0.96 & 0.05 \\
3th & 74 & 1.57 & 47.1 & 0.96 & 0.07 \\
Zone 3 & & & & & \\
1th & 79 & 1.77 & 44.6 & 0.98 & 0.04 \\
2th & 78 & 1.73 & 45.1 & 0.98 & 0.03 \\
3th & 77 & 1.59 & 48.4 & 0.82 & 0.23 \\
Zone 4 & & & & & 0.11 \\
1th & 68 & 1.83 & 37.2 & 0.58 & 0.13 \\
2th & 70 & 1.85 & 37.8 & 0.90 & 0.20 \\
3th & 70 & 1.85 & 37.8 & 0.83 & \\
\hline
\end{tabular}

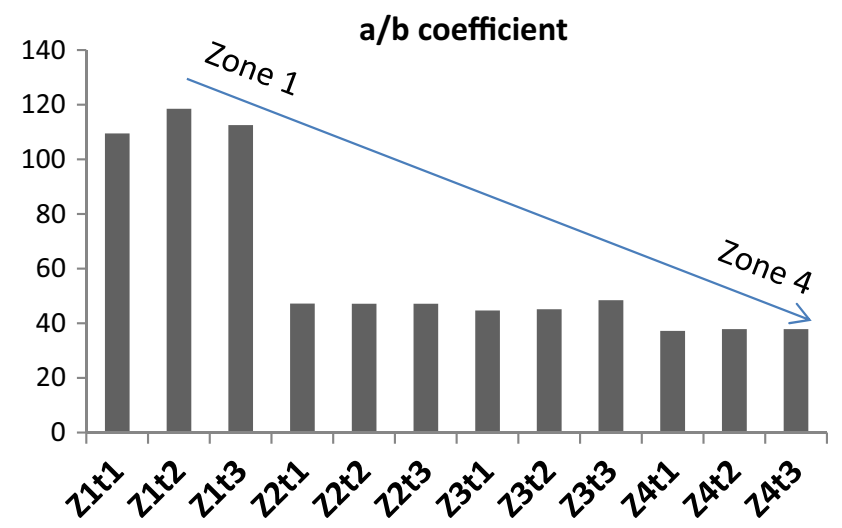

Fig. 3 Changes of a/b coefficient in 4 zones and 3 time of rainfall duration, "Z" represent radar zone and "t" represent rainfall time duration

respect to $b$ more clearly. Both the empirical coefficients (a, b) were strongly dependent. By increasing coefficient (a), the (b) coefficient decreases and vice versa. To better exhibit both changes of variables, we introduce $\mathrm{a} / \mathrm{b}$ parameter. This ratio could manifest effectively the changes of variables better than separate variables. Table 2 shows the values of $a / b$ variable in different times and different zones. We noted the range of $\mathrm{a} / \mathrm{b}$ coefficients are within (37.2-118.5). The (a/b) coefficient changes are attributed to different distance from radar station (zones). Figure 3 shows clearly the changes of new empirical coefficient $(\mathrm{a} / \mathrm{b})$ in different zones. It is also found that $(a / b)$ changes with different time of rainfall. 


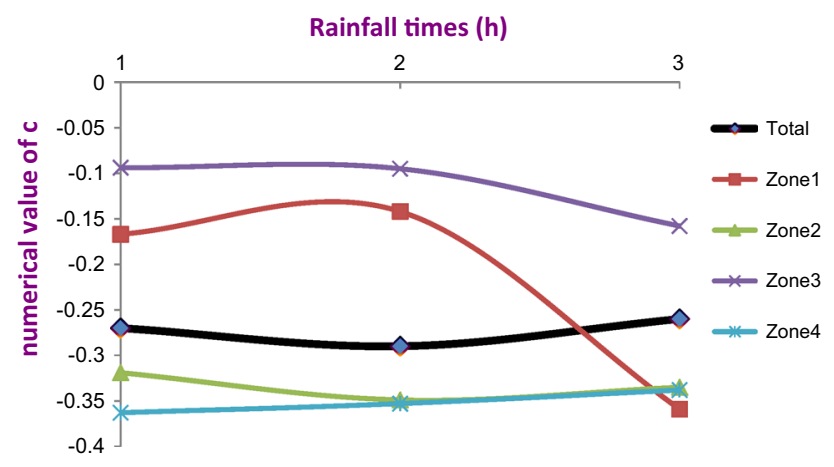

Fig. 4 Changes of (c) coefficient at 4 zones

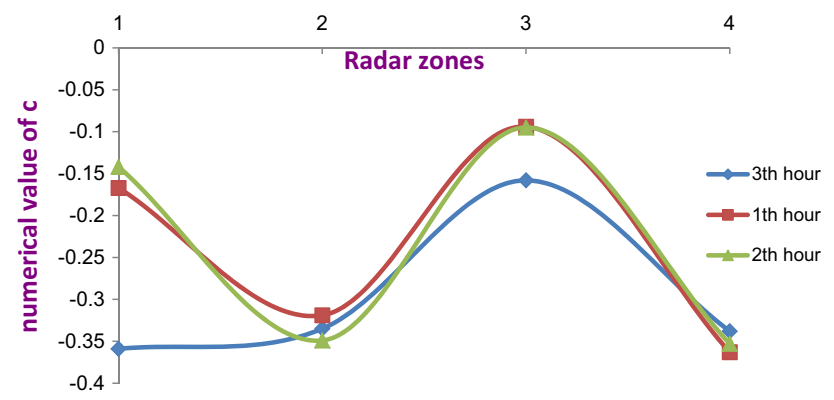

Fig. 5 Changes of (c) coefficient in times and zones

2. The strong exploration relationship were evident among altitudes $(\mathrm{H})$, radar reflectivity $(\mathrm{Z})$ and rainfall amount (R); Z-R-H; according to Eq. (11), $Z=$ $a R^{b} H^{c}+e$ has been proven, there are strong relationship between $\mathrm{Z}-\mathrm{R}-\mathrm{H}$. In the new hypothesized relationship, upon entering $\mathrm{H}$ parameter, the c coefficient is generated. The $\mathrm{c}$ coefficient changes show the condition and characteristic of altitude parameter. The value of this new empirical coefficient is a negative numeric, which infers that reflectivity $(Z)$ with altitude (H) have inversely proportional relationship. Also, at higher elevations, much less radar reflectivity is noted. This can be interpreted based on the convective precipitation at height. The $\mathrm{Z}-\mathrm{R}-\mathrm{H}$ relationship is investigated in all zones and 3 time of rainfall time duration. Figures 4 and 5 shows the amount of new empirical coefficient and relationship between 3 variables in 4 zones and 3 th times of rainfall.

Table 3 shows the value of coefficient $\mathrm{c}$ with respect to other related parameters in all locations (zones) far from the radar station. We found that coefficient $\mathrm{c}$ varies within range of $(-0.094)$ to $(-0.363)$, with significant changes in distant zones. It is clearly evident that the amount of reflectivity is less in distant zones. But in terms of the third zone is different due to the mountainous conditions. It can be explained and justified. This result is not unexpected.
Table 3 Summary of coefficient (a, b, c), R-square and RMSE after use of altitude parameter $(\mathrm{Z}-\mathrm{R}-\mathrm{H})$

\begin{tabular}{crllll}
\hline Time/Coe & \multicolumn{1}{l}{$\mathrm{a}$} & $\mathrm{b}$ & $\mathrm{c}$ & $\mathrm{R} 2(\mathrm{p}<0.05)$ & $\mathrm{RMSE}(\mathrm{mm} / \mathrm{h})$ \\
\hline Zone 1 & & & & & \\
1th & 357 & 0.95 & -0.167 & 0.78 & 0.119 \\
2th & 271 & 0.81 & -0.142 & 0.71 & 0.179 \\
3th & 1363 & 0.87 & -0.359 & 0.82 & 0.185 \\
Zone 2 & & & & & \\
1th & 763 & 1.58 & -0.319 & 0.97 & 0.036 \\
2th & 947 & 1.58 & -0.349 & 0.98 & 0.041 \\
3th & 849 & 1.58 & -0.335 & 0.99 & 0.023 \\
Zone 3 & & & & & \\
1th & 157 & 1.78 & -0.094 & 0.98 & 0.033 \\
2th & 153 & 1.72 & -0.095 & 0.98 & 0.024 \\
3th & 240 & 1.60 & -0.158 & 0.82 & 0.190 \\
Zone 4 & & & & & 0.091 \\
1th & 993 & 1.81 & -0.363 & 0.86 & 0.105 \\
2th & 947 & 1.86 & -0.353 & 0.91 & 0.169 \\
3th & 853 & 1.86 & -0.338 & 0.84 & \\
\hline
\end{tabular}

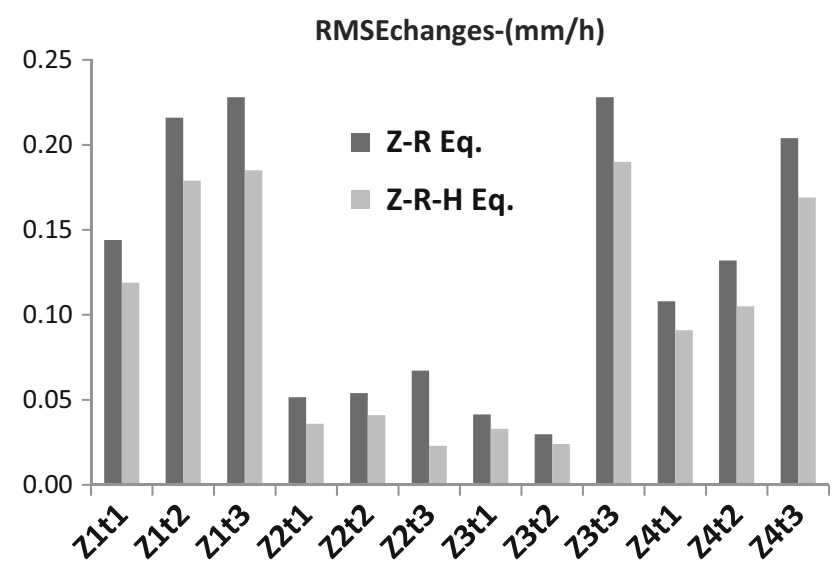

Fig. 6 Changes of RMSE from 4 introduced radar zones and 3 time of rainfall duration before and after use of altitude parameter $(\mathrm{H})$. " $\mathrm{Z}$ " represent radar zone and " $\mathrm{t}$ " represent rainfall time duration

Obtained graphs demonstrated whatever the precipitation time passes; the numerical value of coefficient $c$ has a sinusoidal shape. Further research will show for more rainfall time duration the sinusoidal trend will continue or change. In summary it can be said; Z-R relationship at different heights, various distances from the radar station, even when rainfall begins moment to end rainfall is very changeable. Based on this theory that others parameters are effective and can be entered in the Z-R equation. Therefore, the altitude parameter $(\mathrm{H})$ was entered and confirmed through this study. Changes of RMSE, in simple mode ( $\mathrm{Z}-$ R) and when use altitude parameter $(\mathrm{Z}-\mathrm{R}-\mathrm{H})$ show that new improved algorithm has better fitting. Figure 6 


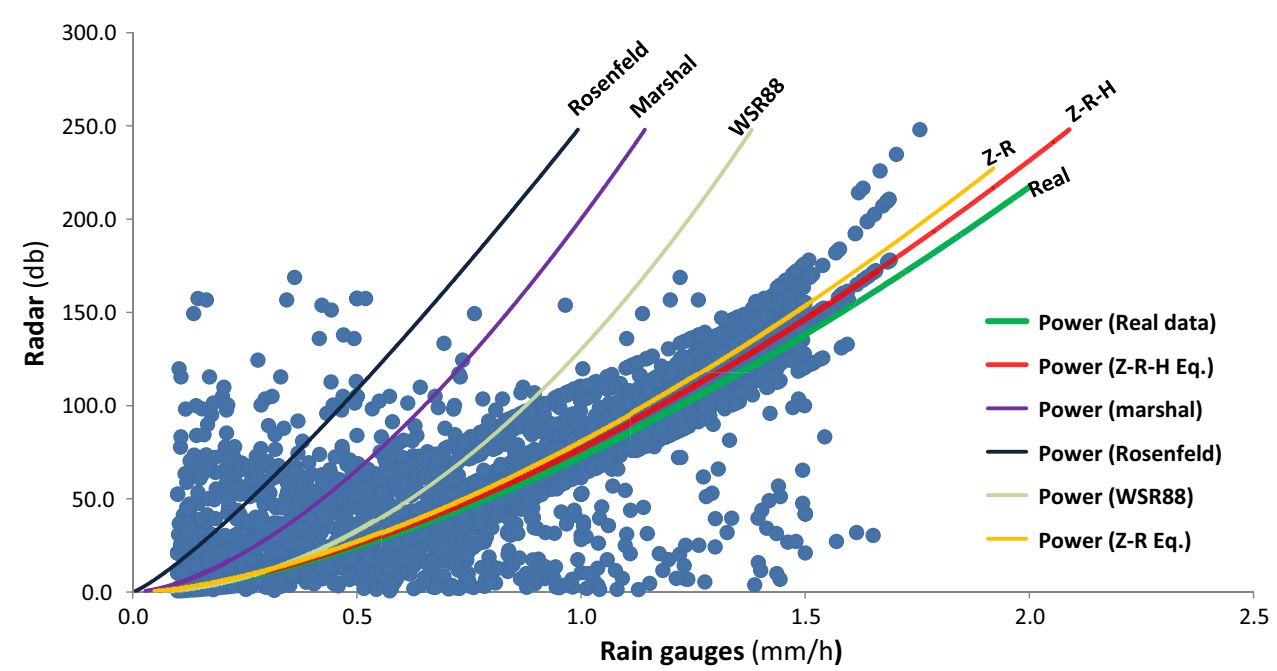

Fig. 7 Fitting of previous model and comparison our algorithm simple mode (Z-R) and use of altitude parameters (Z-R-H) in Tabriz radar located in cold semi-arid region

Table 4 Comparison of Z-R relationships default WSR-88D (Matyas) [35] and the results from this study from simple mode (Z-R) and improved new algorithms $(\mathrm{Z}-\mathrm{R}-\mathrm{H})$

\begin{tabular}{|c|c|c|c|c|c|c|c|}
\hline Equation & $\mathrm{a}$ & $\mathrm{b}$ & $a / b^{*}$ & Relationship title & Researcher & Location of used & RMSE $^{*}$ \\
\hline $\mathrm{Z}=200 \mathrm{R}^{1.6}$ & 200 & 1.6 & 125 & Marshall-Palmer & Marshall-Palmer & Stratiform & 0.34 \\
\hline $\mathrm{Z}=300 \mathrm{R}^{1.4}$ & 300 & 1.4 & 214 & Convective (Default) & WSR-88D & $\begin{array}{l}\text { Summer deep convection, non- } \\
\text { tropical }\end{array}$ & 0.2 \\
\hline $\mathrm{Z}=75 \mathrm{R}^{2.0}$ & 75 & 2 & 38 & West-Cool Stratiform & WSR-88D & $\begin{array}{l}\text { Winter stratiform west of } \\
\text { continental distribution }\end{array}$ & - \\
\hline$Z=130 R^{2.0}$ & 130 & 2 & 65 & East-Cool & WSR-88D & $\begin{array}{l}\text { Stratiform Winter st. east of } \\
\text { continental distribution }\end{array}$ & - \\
\hline $\mathrm{Z}=250 \mathrm{R}^{1.2}$ & 250 & 1.2 & 208 & Rosenfeld Tropical & Rosenfeld & Tropical convection & 0.47 \\
\hline $\mathrm{Z}^{*}=77 \mathrm{R}^{1.58}$ & 77 & 1.58 & 49 & Nikahd-Hashim & This study $^{*}$ & Cold semi-arid, mountainous & 0.14 \\
\hline $\mathrm{Z}^{*}=581 \mathrm{R}^{1.58} \mathrm{H}^{-0.273}$ & & & & & Nikahd-Hashim & Cold semi-arid, mountainous & 0.15 \\
\hline
\end{tabular}

* Undertaken in this article

demonstrate changes of RMSE from 4 introduced radar zones and 3 time of rainfall duration before and after use of altitude parameter (H). Amount of RMSE in new mode (Z$\mathrm{R}-\mathrm{H})$ at 4 zones of radar and 3 times of rainfall is lower than before use of altitude parameter in equation. Figure 7 is fitting the previous equations (Marshall-Palmer, Rosenfeld and WSR 88) and our research with and without altitude parameter. Amount of RMSE confirm that the new $\mathrm{Z}-\mathrm{R}-\mathrm{H}$ equation is able to replace with universal $\mathrm{Z}-\mathrm{R}$ equation (see Table 4).

\section{Discussion}

Using the Z-R-H methodology for unipolar ground-based radar calibration and vagueness estimation gives beneficial and valuable outcomes. This equation is applied on the radar calibration, which suit precisely for unipolar ground- based radar type. The results of this study clearly illustrate that the agreement between radar reflectivity and rainfall amount is highly dependent on altitudes effects. Table 4 summarises the comparison of Z-R relationship obtained with similar previous studies [35]. The value of empirical coefficients from different areas is presented. This study noted Z-R relationship in cold semi-arid for this region, where the coefficients are uniquely representing the region. Also, considering that the other parameters have been ignored in radar rainfall estimation, this study have focused to three effective main parameters in radar rainfall equation that includes: altitudes effects, distance from radar and rainfall time duration. Accordingly, to investigate the effectiveness of distance from radar, radar coverage area was divided into 4 zones. To determine the altitudes impact, altitude for all rain gauges were interfered in the equation. The first three hours of rainfall was considered in order to enable detection of changes in rainfall in initial 
precipitation and subsequent periods. According the previous studies that is illustrated in Table 4, the amount of empirical coefficient is very changeable in different region. In many climate zones, these empirical coefficient are still have not investigated and determined. In this study the empirical coefficients for cold semi-arid region is defined. Also the altitude parameter $(\mathrm{H})$ is used to more accurately predict rainfall. Although previous research has identified the value of empirical coefficient briefly, here the value of empirical coefficient ( $a, b, a / b$ and $c$ ) at different distances from the radar and duration of the precipitation has been determined. This study is one step ahead of the results of previous studies in order to radar rainfall estimation. Findings obtained from the results are commonly used for meteorology and hydrological applications, hence this is beneficial particularly important to similar regions of study. Result of this paper, strongly confirm to use of this improved method $(\mathrm{Z}-\mathrm{R}-\mathrm{H})$, to achieve the accurate results in radar-rainfall for hydrometeorology application.

This equation is applied on the radar calibration, which is precisely suited for unipolar ground-based radar types. The results of this study clearly illustrate that the agreement between radar reflectivity and rainfall amount is highly dependent on rang effects (distance from radar station and rainfall location). This study noted the Z-R relationship in a semi-arid region, where the coefficients are uniquely representing the region. Also, considering that the other parameters have been ignored in radar rainfall estimation, this study has focused on three effective main parameters in the radar rainfall equation: altitudes effects, distance from radar and rainfall time duration. Accordingly, to investigate the effectiveness of distance from radar, the radar coverage area was divided into 4 zones (0-50, 50-100, 100-150, 150-200 km). Tables 2 and 3 illustrate the amount of correlation coefficient and RMSE from each rainfall location far from the radar station. The result of this table can satisfy Geographically Weighted Regression (GWR) from each place far from the radar. Also to determine the altitudes impact, altitude for all rain gauges were interfered in the equation. The first $3 \mathrm{~h}$ of rainfall were considered in order to enable detection of changes in rainfall during initial precipitation and subsequent periods. Findings obtained from the results are commonly being used in meteorology and hydrological applications; hence this is beneficial and closely aligned with similar fields of study.

\section{$\mathrm{Z}-\mathrm{R}$ relationship and $\mathbf{a} / \mathrm{b}$ parameterization}

We noted strong relationship $\left(\mathrm{R}_{\min }^{2}=0.70, \mathrm{R}_{\max }^{2}=0.98\right)$ between radar reflectivity and the amount of rainfall $(Z-R)$, in the cold semi-arid zone in geographic middle latitude of northern hemisphere. Empirical coefficient changes presented relevant correlation in different situation and location far from the radar. According Table 4, amount of (a and b) coefficient have separately considered previous studies. In this study, first time changes of empirical coefficient is considered $(\mathrm{a} / \mathrm{b})$ style, because their changes are dependent together strongly. The new $\mathrm{a} / \mathrm{b}$ coefficient expressed the changes empirical coefficient far from the radar. As it is distant away from the radar station, $a / b$ coefficient is decreases, hence indicating that radar echoes are less returning to receiver from far radar stations. This result is not unexpected, because the uncertainty resources have a large impact on the amount reflectivity. It is evident that all the empirical coefficients does not change with different time of rainfall.

Nonetheless, there is no considerable $\mathrm{a} / \mathrm{b}$ coefficients changes in first to third time of rainfall occurrence. Evidently, there are minor changes, but cannot be fully interpreted at this point time as evident do not follow a logical sequence. The benefit of the $a / b$ is obvious that it represents the changes of amount of rainfall corresponding radar reflectivity in far from the radar (distance) and duration of rainfall time. After this, in order to radar adjustment it is better to use $a / b$ coefficient instead (a) and (b) coefficients independently. Especially in urban areas for flood control that needs to be more careful. New coefficient $(a / b)$ has the ability to show characteristic of region better than last empirical coefficients. It can be a strong default for groundbased radar in different geographic latitude prior to anticipated operations. The $\mathrm{a} / \mathrm{b}$ changes at different times of rainfall and different distances away from the radar, prove this assumption that; for each region and each climatic situation, have to be synthesized exclusively Radar-rainfall (Z-R). We synthesized this relationship for cold semi-arid region.

\section{Z-R-H approach and introduce c coefficient}

The altitudes parameters entry in radar equation is the first attempt in this study, but this is very crucial in this field of study. Given that the others parameters in the $\mathrm{Z}-\mathrm{R}$ relationship can be effective, altitude $(\mathrm{H})$ parameter is entered and for first time $\mathrm{Z}-\mathrm{R}-\mathrm{H}$ is defined. In the new hypothesized relationship, upon entering $\mathrm{H}$ parameter, the c coefficient is generated. The c coefficient changes show the condition and characteristic of altitude parameter. Figure 8 schematically shows the general shape of the $\mathrm{Z}-\mathrm{R}-\mathrm{H}$ genesis, as discussed in this article. As the case study (Azarbayjan province) is a relatively mountainous area, parameter $\mathrm{H}$ with coefficient $\mathrm{c}$ changes are explainable in different location and times. The $c$ coefficient changes shows the effect of rainfall types (mountainous and conventional) in radar-rainfall relationship. Maximum value of R-square and minimum RMSE in different time and 


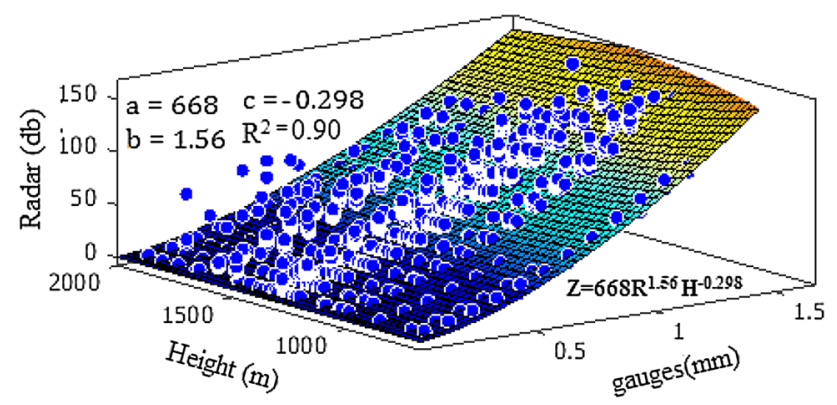

Fig. 8 A sample of the general shape of the Z-R-H genesis in the model

different location shows there are strong relationship between 3 parameters; namely the Z-R-H. The c coefficient changes ranges are $(-0.094)$ to $(-0.363)$. We noted $c$ coefficients are negative values. These negative value in power of altitude parameter $\left(H^{-c}\right)$ display that at higher altitudes the return echo $(\mathrm{Z})$ is lower than flat areas, and this is agreeable to amount of precipitation at higher altitudes is more than plain. In the other word, negative values of c coefficient means: with constant radar reflectivity in the higher elevations, precipitation volume is higher. These results can interpret amount of mountainous precipitation in radar-rainfall equation. As illustrated in the Figs. 6 and 7 an inevitable consequence of the $Z=a R^{b} H^{c}$ relationship is that the $\mathrm{H}$ parameter and c coefficient becomes the main part of radar-rainfall equation $(Z-R)$ for future users in hydrometeorology. The ultimate amount of $\mathrm{Z}-\mathrm{R}-\mathrm{H}$ relationship for cold semi-arid zone, is obtained; $\mathrm{Z}^{*}=581$ $\mathrm{R}^{1.58} \mathrm{H}^{-0.273}$.

The results of this study also well indicated that coefficient $\mathrm{c}$ alternate from first time of rainfall to other next times. As precipitation time passes; the numerical value of coefficient $\mathrm{c}$ has a sinusoidal shape. Obviously, the level of this claim is a discussable theory. Further research will show for more rainfall time duration the sinusoidal trend will continue or no. Notable issue is that, there is no $\mathrm{a} / \mathrm{b}$ coefficient changes in duration of rainfall times but coefficient $\mathrm{c}$ varies considerably. As demonstrated in Fig. 6, it is an advantage if the radar rainfall measurement is conducted based on Z-R-H relationship in different time as well, which in itself suggests the use of the most effective parameter. Also, the new relationship is very useful in watershed hydrology management, because the duration of precipitation and distance from the location of the precipitation from basin outlet is very important, especially in flood routing and flash flood control. Although, the authors have considered the new relationship in order to allow radar calibration, it is not doubtful that any improvement by using other effective parameters will be highly rational (Fig. 9).

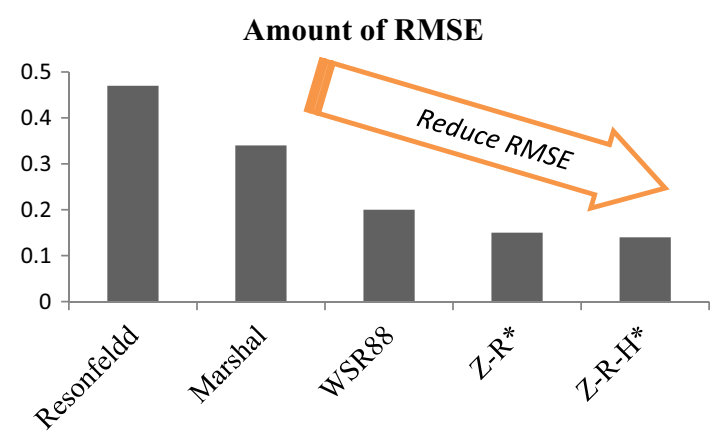

Fig. 9 Amount of RMSE after fitting data by previous model and our new improved algorithm, amount of RMSE is for rainfall (mm) per one hour as base of time study

\section{Conclusion}

The research outcomes had demonstrated that the radar relationship is so important exclusively if the data is to be used in hydrometeorology applications, which require high resolutions in time and space. Therefore, it is concluded that the use of other effective parameters (distance from radar, altitudes and rainfall time duration) leads to optimum accuracy of Z-R relationship. Strong relationship between radar-rainfall-altitude is also evident. Moreover, there were rational correlation between empirical coefficient and new coefficient (altitude coefficient) in different rainfall time duration and different distance from radar (zones). It is very important that the radar-rainfall-altitude relationship is treated as an instantaneous method for rainfall estimation. In order to improve radar-rainfallaltitude relationship, it is highly recommended to apply other effective parameters in different rainfall time situation and location, especially in mountainous areas. According to the objectives of this study; the results show the range effects of radar to rainfall estimation and the influence of elevation in the relationship between radarreflectivity and real-rainfall amount is determined. The results illustrate the relationship of range and elevation with respect to different geographical latitudes. So, with the involvement of the elevation parameter $(\mathrm{H})$, the $\mathrm{Z}-\mathrm{R}$ equation was used to develop the $\mathrm{Z}-\mathrm{R}-\mathrm{H}$ equation. It is necessary to apply this experiment with more rainfall time duration and much more registered rain gauges under radar supervision. Finally, this new contribution is crucial for minimizing uncertainties for accurate rainfall measurement and related-derived hydrological parameters to for input into various tasks in sustainable water resource management especially in ensuring water security and mitigating rainfall-based disasters.

Acknowledgments We are thankful to the Universiti Teknologi Malaysia (UTM) for providing the facilities for this investigation. The 
financial assistance of UTM Research University grant for satellitebased multisensor water yield study is also acknowledged.

\section{Compliance with ethical standards}

Conflict of interest Also in this article authors have no conflict of interest.

Open Access This article is distributed under the terms of the Creative Commons Attribution 4.0 International License (http://creative commons.org/licenses/by/4.0/), which permits unrestricted use, distribution, and reproduction in any medium, provided you give appropriate credit to the original author(s) and the source, provide a link to the Creative Commons license, and indicate if changes were made.

\section{References}

1. Barthès L, Mallet C (2013) Rainfall measurement from the opportunistic use of an Earth-space link in the Ku band. Atmos Meas Tech [Internet] 6(8):2181-2193. http://www.atmos-meastech.net/6/2181/2013/ (cited 2014 Mar 31)

2. Dai Q, Rico-Ramirez MA, Han D, Islam T, Liguori S (2014) Probabilistic radar rainfall nowcasts using empirical and theoretical uncertainty models. Hydrol Process [Internet] 1-8. doi:10. 1002/hyp.10133 (cited 2014 Mar 31)

3. Nielsen JE, Beven K, Thorndahl S, Rasmussen MR (2014) GLUE based marine X-band weather radar data calibration and uncertainty estimation. Urban Water J [Internet]. Taylor \& Francis 00(0):1-12. doi:10.1080/1573062X.2013.871044 (cited 2014 Mar 31)

4. Nielsen JE, Thorndahl S, Rasmussen MR (2014) A numerical method to generate high temporal resolution precipitation time series by combining weather radar measurements with a nowcast model. Atmos Res [Internet]. Elsevier B.V. 138:1-12. http://linkinghub. elsevier.com/retrieve/pii/S0169809513002883 (cited 2014 Mar 31)

5. Villarini G, Seo B-C, Serinaldi F, Krajewski WF (2014) Spatial and temporal modeling of radar rainfall uncertainties. Atmos Res [Internet]. Elsevier B.V. 135-136:91-101. http://linkinghub.else vier.com/retrieve/pii/S0169809513002482 (cited 2014 Mar 31)

6. Atlas D (2004) Radar calibration-some simple new approach [Internet]. Workshop radar calibration. doi:10.1002/cbdv. 200490137/abstract

7. Pedersen L, Jensen NE, Madsen H (2010) Calibration of local area weather radar-identifying significant factors affecting the calibration. Atmos Res [Internet]. Elsevier B.V. 97(1-2):129-143. http://linkinghub.elsevier.com/retrieve/pii/S0169809510000657 (cited 2012 May 7)

8. Thorndahl S, Rasmussen MR (2012) Marine X-band weather radar data calibration. Atmos Res [Internet]. Elsevier B.V. 103:33-44. http://linkinghub.elsevier.com/retrieve/pii/S0169809511001359 (cited 2012 Mar 15)

9. Prat O, Barros A (2009) Exploring the transient behavior of Z-R relationships: implications for radar rainfall estimation. 2127-2143. doi:10.1175/2009JAMC2165.1

10. Mandapaka P V., Krajewski WF, Ciach GJ, Villarini G, Smith JA (2009) Estimation of radar-rainfall error spatial correlation. Adv Water Resour [Internet]. Elsevier Ltd 32(7):1020-1030. http:// linkinghub.elsevier.com/retrieve/pii/S0309170808001486 (cited 2012 Mar 8)

11. Chumchean S, Sharma A, Seed A (2003) Radar rainfall error variance and its impact on radar rainfall calibration. Phys Chem Earth 28:27-39

12. Andrieu H, French MN, Krajewski WF, Georgakakos KP (2003) Stochastic-dynamical rainfall simulation based on weather radar volume scan data. Adv Water Resour [Internet]. 26(5):581-93. http://linkinghub.elsevier.com/retrieve/pii/S0309170802001689 (cited 2012 May 26)

13. Alfieri L, Claps P, Laio F (2010) Time-dependent Z-R relationships for estimating rainfall fields from radar measurements. Nat Hazards Earth Syst Sci 1973:149-158

14. Suk M-K, Chang K-H, Cha J-W, Kim K-E (2013) Operational realtime adjustment of radar rainfall estimation over the South Korea region. J Meteorol Soc Japan Ser II [Internet] 91(4):545-554. http:// jlc.jst.go.jp/DN/JST.JSTAGE/jmsj/2013-409?lang=en\&from=Cross Ref\&type=abstract. (cited 2014 Mar 30)

15. Uijlenhoet R (2001) Raindrop size distributions and radar reflectivity-rain rate relationships for radar hydrology*. Hydrol Earth Syst Sci 5(4):615-627

16. Mapiam PP, Sriwongsitanon N, Chumchean S, Sharma A (2009) Effects of rain gauge temporal resolution on the specification of a Z$\mathrm{R}$ relationship. J Atmos Ocean Technol [Internet] 26(7):1302-1314. doi:10.1175/2009JTECHA1161.1 (cited 2012 May 16)

17. Yeo JX, Lee Y-H, Kumar LS, Ong JT (2012) Comparison of S-band radar attenuation prediction with beacon measurements. IEEE Trans Antennas Propag [Internet] 60(10):4892-4900. http://ieeexplore. ieee.org/lpdocs/epic03/wrapper.htm?arnumber=6236096

18. Ryzhkov AV, Giangrande SE, Melnikov VM, Schuur TJ (2005) Calibration issues of dual-polarization radar measurements. J Atmos Ocean Technol 22:1138-1155

19. Giangrande SE, Ryzhkov AV (2005) Calibration of dual-polarization radar in the presence of partial beam blockage. J Atmos Ocean Technol 22:1156-1166

20. Van de Beek CZ, Leijnse H, Stricker JNM, Uijlenhoet R, Russchenberg HWJ (2010) Performance of high-resolution X-band radar for rainfall measurement in The Netherlands. Hydrol Earth Syst Sci [Internet] 14(2):205-221. http://www.hydrol-earth-systsci.net/14/205/2010/

21. Yu XT, Yu ZW, Rui XP, Li F, Xi YT, Chen HQ (2012) Discussion about the determination methods of weighted centroid of dBZ on vector radar echoes. Proc Eng [Internet] 29:2240-2246. http://linkinghub.elsevier.com/retrieve/pii/S1877705812003050 (cited 2012 May 16)

22. Krajewski WF, Vignal B, Seo B-C, Villarini G (2011) Statistical model of the range-dependent error in radar-rainfall estimates due to the vertical profile of reflectivity. J Hydrol [Internet]. Elsevier B.V. 402(3-4):306-316. http://linkinghub.elsevier.com/retrieve/ pii/S0022169411002046 (cited 2012 May 16)

23. Morin E, Maddox RA, Goodrich DC, Sorooshian S (2005) Radar Z-R relationship for summer monsoon Storms in Arizona. Weather Forecast 20:672-679

24. Mapiam P, Sriwongsitanon N (2008) Climatological Z-R relationship for radar rainfall estimation in the upper Ping river basin. Sci Asia 34(1513):215-222

25. Henschke A (2009) Adjustment of the Z-R relationship in realtime for use in South Florida. World environmental and water resources congress 2009 ASCE. pp 6069-80

26. Chumchean S, Seed A, Sharma A (2008) An operational approach for classifying storms in real-time radar rainfall estimation. J Hydrol [Internet]. Elsevier B.V. 363(1-4):1-17. http:// linkinghub.elsevier.com/retrieve/pii/S0022169408004812 (cited 2012 Mar 26)

27. Gabella M, Bolliger M, Germann U, Perona G (2005) Large sample evaluation of cumulative rainfall amounts in the Alps using a network of three radars. Atmos Res [Internet] 77(1-4):256-68. http://linkinghub.elsevier.com/retrieve/pii/ S0169809505001043 (cited 2012 Dec 15)

28. Ozturk K, Yilmazer AU (2007) Improving the accuracy of the radar rainfall estimates using gage adjustment techniques: Case study for west Anatolia, Turkey. Atmos Res [Internet] 
86(2):139-148.

http://linkinghub.elsevier.com/retrieve/pii/ S016980950700066X (cited 2012 May 26)

29. Bruen M, O'Loughlin F (2013) Towards a nonlinear radar-gauge adjustment of radar via a piece-wise method. Meteorol Appl [Internet].1-9. doi:10.1002/met.1390 (cited 2014 Mar 30)

30. Villarini G, Krajewski WF (2009) Review of the different sources of uncertainty in single polarization radar-based estimates of rainfall. Surv Geophys [Internet] 31(1):107-129. doi:10.1007/ s10712-009-9079-x (cited 2012 May 26)

31. Nielsen JE, Jensen NE, Rasmussen MR (2012) Calibrating LAWR weather radar using laser disdrometers. Atmos Res [Internet]. Elsevier B.V. http://linkinghub.elsevier.com/retrieve/pii/ S0169809512003432 (cited 2012 Nov 21)

32. Gabella M, Michaelides S (2007) Adjusting ground radar using space TRMM precipitation radar. Advances in measurement, estimation and prediction, 1st edn. Springer, Berlin, pp 493-514
33. Looper JP, Vieux BE (2012) An assessment of distributed flash flood forecasting accuracy using radar and rain gauge input for a physics-based distributed hydrologic model. J Hydrol [Internet]. Elsevier B.V. 412-413:114-132. http://linkinghub.elsevier.com/ retrieve/pii/S002216941100374X (cited 2012 Oct 29)

34. Krajewski WF, Smith JA (2002) Radar hydrology: rainfall estimation. Adv Water Resour [Internet]. 25(8-12):1387-1394. http://linkinghub.elsevier.com/retrieve/pii/S0309170802000623

35. Matyas CJ (2010) Use of ground-based radar for climate-scale studies of weather and rainfall. Geogr Compass [Internet] 4(9):1218-1237. doi:10.1111/j.1749-8198.2010.00370.x 